\title{
Evaluation of host-guest complex formation between a benzimidazolic derivative and cyclodextrins by UV-VIS spectrophotometry and differential scanning calorimetry
}

\author{
Ana Figueiras · Laura Ribeiro $\cdot$ \\ J. J. Torres-Labandeira $\cdot$ Francisco J. B. Veiga
}

Received: 15 May 2006/ Accepted: 20 October 2006/ Published online: 20 February 2007

(C) Springer Science+Business Media B.V. 2007

\begin{abstract}
Interactions between a benzimidazolic derivative, omeprazole (OME), beta-cyclodextrin $(\beta \mathrm{CD})$ and a chemically modified $\beta \mathrm{CD}$, methyl-betacyclodextrin $(\mathrm{M} \beta \mathrm{CD})$ were investigated in aqueous solution by UV-VIS spectroscopy and in solid state by differential scanning calorimetry (DSC). Phase solubility studies were used to evaluate the complexation in aqueous solution. The two solubility diagrams obtained were $A_{L}$ type, indicating the formation of a drugcyclodextrin complex with 1:1 stoichiometry. The complex of OME with $\mathrm{M} \beta \mathrm{CD}$ showed a higher stability constant $\left(K_{\mathrm{S}}\right)$ than those with $\beta \mathrm{CD}$. Some evidences of inclusion complexation in solid state were obtained from DSC. Only in thermal curves of OME- $\beta$ CD lyophilized product and in OME-M $\beta \mathrm{CD}$ spray-dried and lyophilized systems the melting point of the drug disappeared completely suggesting the possible formation of an inclusion complex.
\end{abstract}

Keywords Cyclodextrins - Differential scanning calorimetry (DSC) - Inclusion complex · Omeprazole · Phase solubility studies

\footnotetext{
A. Figueiras · Francisco J.B. Veiga ( $\square)$

Laboratory of Pharmaceutical Technology, Faculty of Pharmacy, University of Coimbra, Coimbra 3000-295, Portugal

e-mail: fveiga@ci.uc.pt
}

\author{
A. Figueiras - L. Ribeiro - Francisco J.B. Veiga \\ Pharmaceutical Studies Center, Faculty of Pharmacy, \\ University of Coimbra, Coimbra, Portugal

\section{J. J. Torres-Labandeira} \\ Laboratory of Pharmaceutical Technology, Faculty of \\ Pharmacy, University of Santiago de Compostela, Santiago \\ de Compostela, Spain
}

\section{Introduction}

Omeprazole (OME) is a substituted benzimidazole that inhibits gastric acid secretion by covalently binding to the proton pump $\left(\mathrm{H}^{+} / \mathrm{K}^{+}\right.$ATPase $)$at the surface of gastric parietal cells, which inhibit the final step in secretion of the hydrogen ions into the gastric lumen [1]. However, OME is sparingly soluble in water and shows a low physicochemical stability. This poor aqueous solubility of the drug gives rise to difficulties in the pharmaceutical formulation. To overcome this drawback, the increase of the aqueous solubility of OME is very important.

The potential use of natural cyclodextrins (CDs) and their synthetic derivatives has been extensively studied to improve certain drug properties such as solubility, stability, and/or bioavailability. The property of enhancing solubility may be explained by the formation of water-soluble "inclusion complexes" in which the hollow, truncated, cone-like CD structure encapsulates the hydrophobic drug molecules in the apolar interior. In contrast, the outer, hydrophilic region of the $\mathrm{CD}$ enables the solubilization through interaction with water molecules [2]. Nevertheless, natural CDs have limited water solubility. In order to obtain a significant increase in water solubility, some chemically derivatives have been synthesized by derivatization of the free hydroxyl groups of the CDs with alkyl and sulfobutyl groups resulting in hydroxyalkyl, methyl, and sulfobutyl derivatives with higher water solubility [3].

In a thorough study of an inclusion complex, phase solubility studies are the first tool to provide evidence of an inclusion complex formation in solution. At the solid state, the subsequent phases of inclusion complex characterization may be provided by differential scanning 
calorimetry (DSC), X-ray powder diffraction, Fourier transformation infrared spectroscopy. Thermal analysis is commonly used as a routine method for a rapid preliminary qualitative investigation by comparing the thermal behavior of single components, their physical mixture and the inclusion compound candidate prepared according to a variety of standard procedures [4].

The aim of this work was to investigate the formation of an inclusion complex between omeprazole, a poorly water soluble drug, and $\beta$-cyclodextrin $(\beta C D)$ or its amorphous derivative methyl- $\beta$-cyclodextrin $(\mathrm{M} \beta \mathrm{CD})$, in solution by phase solubility studies and in solid state by DSC.

\section{Materials and methods}

\section{Chemicals}

$\beta \mathrm{CD}$ (Lot $768237 ; \mathrm{MW}=1135$ ) and $\mathrm{M} \beta \mathrm{CD}$ (Lot 768240 ; $\mathrm{MW}=1190$ with an average degree of substitution DS $=0.5$ ) were a gift from Roquette (Lestrem, France). OME (Lot 18104; MW = 345.42) was kindly donated by Belmac Laboratory, S.A. (Barcelona, Spain). All other reagents were of the highest purity available from commercial sources.

Phase solubility studies

Phase solubility studies were carried out at room temperature $\left(21 \pm 1^{\circ} \mathrm{C}\right)$ according to the method of Higuchi and Connors [5]. Excess amounts of OME were weighted in glass flasks to which were added $10 \mathrm{~mL}$ of boric/borate buffer $\mathrm{pH}=10 \pm 0.1$ containing increasing amounts of $\beta \mathrm{CD}(0-1.5 \%, \mathrm{w} / \mathrm{v})$ or $\mathrm{M} \beta \mathrm{CD}$ $(0-5 \%$, w/v). Glass containers were sealed and mechanically stirred, protected from light until reaching the equilibrium (about $96 \mathrm{~h}$ ). All suspensions were filtered through a $0.45 \mu \mathrm{m}$ membrane filter (Millipore) and analyzed spectrophotometrically (UV-1603, Shimadzu, Japan) at $305.5 \mathrm{~nm}$.

The apparatus was calibrated with the corresponding blank for each assay and three replicates were made. $K_{\mathrm{S}}$ were calculated from the straight line of the phase solubility diagrams using the equation:

$K_{\mathrm{S}}=$ slope $/$ intercept $(1-$ slope $)$

Preparation of solid binary systems

The preparation of OME: $\beta \mathrm{CD}$ and OME:M $\beta \mathrm{CD}$ solid systems was performed by different techniques, namely by kneading, spray-drying and freeze-drying in a molar ratio of 1:1. Physical mixtures were prepared as references to perform comparative evaluations with the respective solid inclusion complexes.

\section{Physical binary mixtures (PM)}

PMs were prepared by homogeneous blending in a mortar of previously sieved $(63-160 \mu \mathrm{m}$ sieve granulometric fraction) and weighted OME and CDs ( $\beta C D$ and $\mathrm{M} \beta \mathrm{CD}$ ).

\section{Kneaded binary products (KN)}

CDs were wetted in a ceramic mortar with a basic aqueous solution of $\mathrm{pH}=10 \pm 0.1$ until a paste was obtained (about $30 \%$ of the total weight). The required amount of OME was then slowly added and the slurry was kneaded for $45 \mathrm{~min}$. During this process, an appropriate volume of a basic aqueous solution ( $\mathrm{pH}=10$ ) was added in order to maintain a suitable consistency and to avoid OME degradation. The final product was then allowed to equilibrate at room temperature for $48 \mathrm{~h}$ protected from light.

\section{Spray-dried binary products $(S D)$}

Equimolar amounts of OME and CDs were dissolved in ethanol and basic aqueous solution (hydro-alcoholic solution 2:1), respectively. Both solutions were mixed and stirred for $24 / 48 \mathrm{~h}$, being the $\mathrm{pH}$ of the solutions adjusted during the process to avoid the possible OME degradation. Solutions were subsequently spray-dried in a LabPlant SD-05, under the following conditions: inlet temperature $102^{\circ} \mathrm{C}$, outlet temperature $60-65^{\circ} \mathrm{C}$, flow rate of the solution $400 \mathrm{~mL} / \mathrm{h}$, airflow rate $40-50 \mathrm{~m}^{3} / \mathrm{h}$ and atomizing air pressure $1.0-1.1$ bar. [6]

\section{Lyophilized binary products $(L P h)$}

An appropriate amount of CDs was dissolved to a basic aqueous solution $(\mathrm{pH}=10 \pm 0.1)$. After that, OME was added to this solution under stirring, according to the stoichiometry $1: 1$. The suspension stirring was maintained for $24 / 48 \mathrm{~h}$. Furthermore, the resultant clear solutions were frozen by immersion in an ethanol bath at $-50{ }^{\circ} \mathrm{C}$ (Shell Freezer, Labconco, Freezone ${ }^{\circledR}$ model 79490) and then the frozen solutions were lyophilized in a freeze-dryer (Lyph-lock 6 apparatus, Labconco) for $72 \mathrm{~h}$.

The obtained powders were sieved $(63-160 \mu \mathrm{m})$ and their drug content was determined by UV assay at $305.5 \mathrm{~nm}$. 
Differential scanning calorimetry

DSC measurements of the pure materials (OME and CDs) and binary systems were carried out using a Shimadzu DSC-50 System (Shimadzu, Kyoto, Japan) with a DSC equipped with a computerized data station TA-50WS/PC. The thermal behaviour was studied by heating the samples in a sealed aluminium pan from $25^{\circ} \mathrm{C}$ to $250^{\circ} \mathrm{C}$, at a rate of $10^{\circ} \mathrm{C} / \mathrm{min}$ and under a nitrogen flow of $20 \mathrm{~cm}^{3} / \mathrm{min}$., using an empty pan sealed as reference. Indium $\left(99.98 \%, \mathrm{mp} 156.65^{\circ} \mathrm{C}\right.$, Aldrich $^{\circledR}$, Milwaukee, USA) was used as standard for calibrating the temperature.

\section{Results}

Phase solubility studies

Phase solubility studies of OME with $\beta \mathrm{CD}$ and $\mathrm{M} \beta \mathrm{CD}$ are shown in Fig. 1. OME solubility increased linearly over the entire concentration range studied with both CDs concentrations, indicating the formation of $A_{L}$ type diagrams. The slope values were in both diagrams
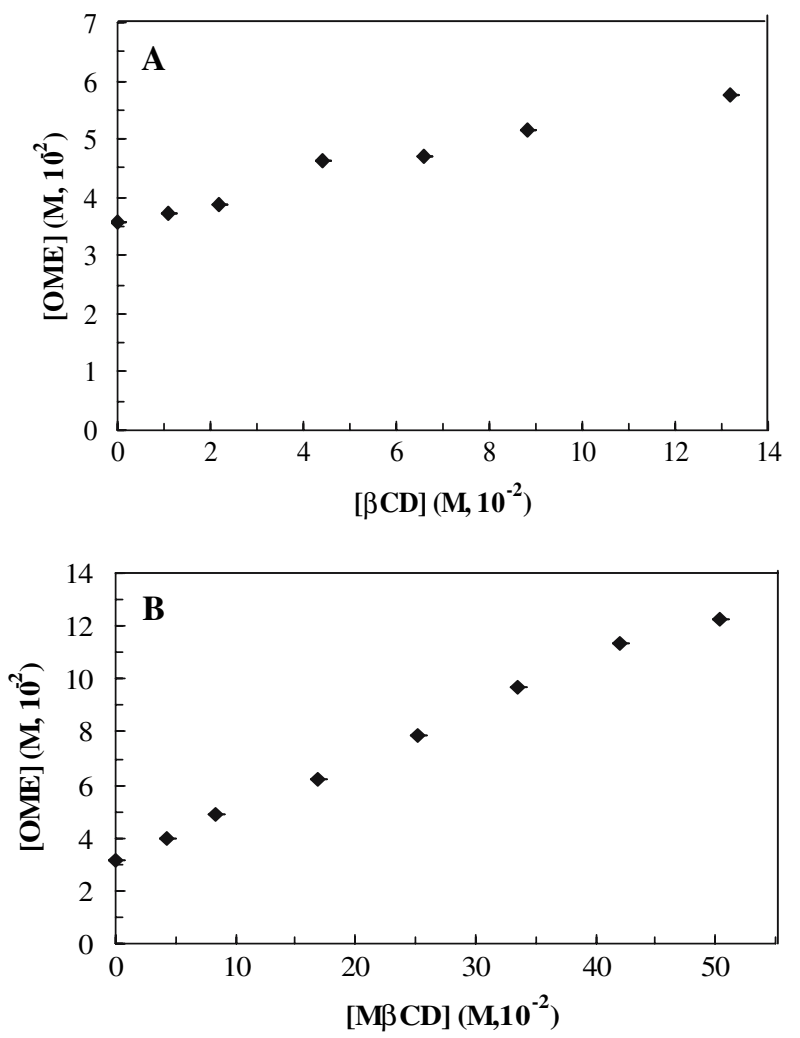

Fig. 1 Phase solubility studies of OME with CDs: $\beta C D(\mathbf{A})$ and $\mathrm{M} \beta \mathrm{CD}(\mathbf{B})$. Each point represents the mean of three determinations less than one suggesting the formation of 1:1 stoichiometry complexes in solution. The OME solubility was enhanced 1.6 and 3.6 times in the presence of $\beta \mathrm{CD}$ and $\mathrm{M} \beta \mathrm{CD}$, respectively, in comparison with $\mathrm{OME}$ solubility in buffer borate (see Fig. 2). The $K_{\mathrm{S}}$ of the inclusion complexes were 57 and $77 \mathrm{M}^{-1}$ for $\beta \mathrm{CD}$ and $\mathrm{M} \beta \mathrm{CD}$, respectively. Values of OME solubility with and without CDs are collected in Table 1. The low magnitude of these stability constants indicated a weak interaction between the drug (OME) and both CDs. In fact at $\mathrm{pH}=10$, to assure drug stability, OME is in the ionized form. However, drug ionization greatly reduces

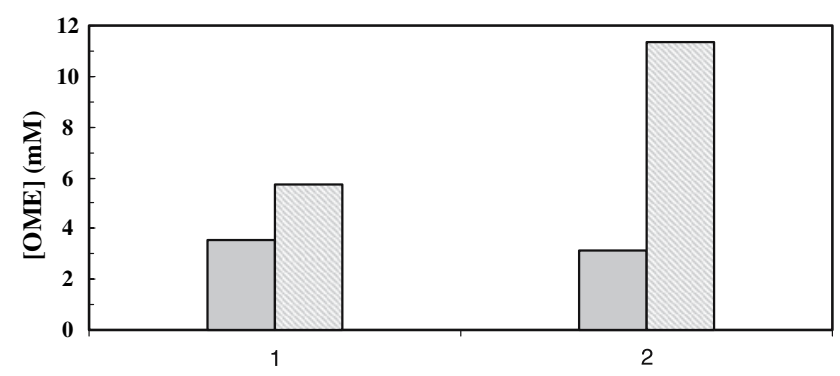

Fig. 2 OME solubility in borate buffer ( $\square$ ) and OME solubility in $\mathrm{CDs}$ solutions $[1.5 \%(\mathrm{w} / \mathrm{v}) \beta \mathrm{CD}$ and $5 \%(\mathrm{w} / \mathrm{v})$ $\mathrm{M} \beta \mathrm{CD}]$, ( $)$. (1) $\beta \mathrm{CD}$ and (2) $\mathrm{M} \beta \mathrm{CD}$
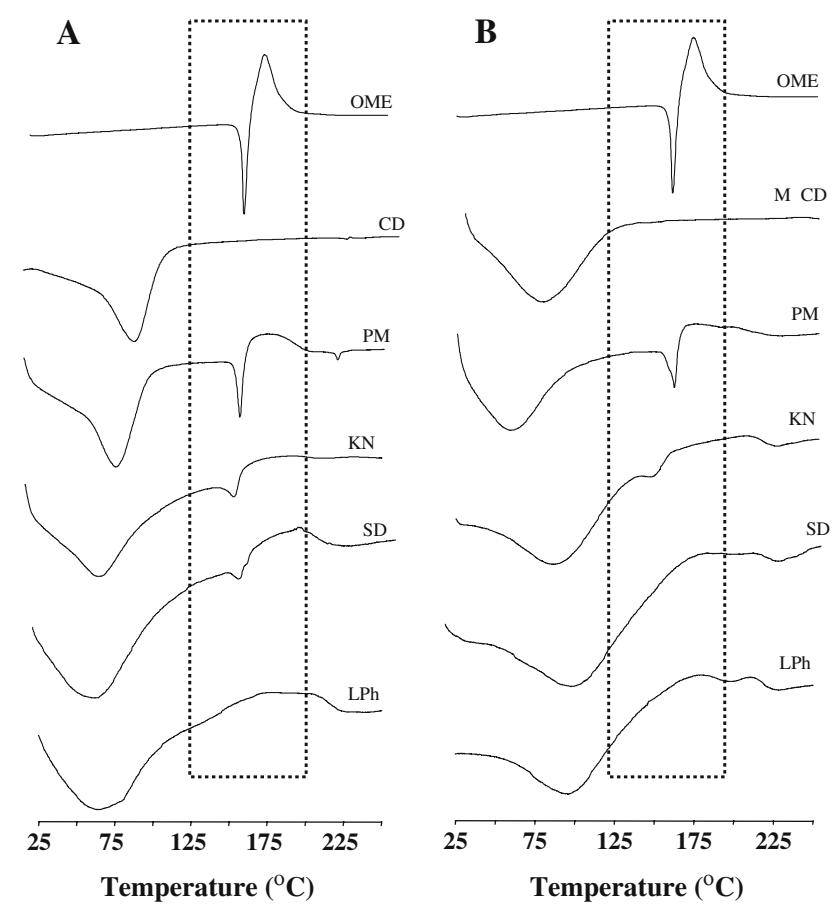

Fig. 3 DSC thermograms of OME: $\beta \mathrm{CD}(\mathbf{A})$ and OME:M $\beta \mathrm{CD}$ (B) inclusion complexes. Omeprazole (OME), $\beta$-cyclodextrin $(\beta \mathrm{CD})$, methyl- $\beta$-cyclodextrin $(\mathrm{M} \beta \mathrm{CD})$, physical mixture (PM), kneaded (KN), spray dried (SD) and lyophilized (LPh) systems 
Table 1 Values of stability constant $\left(K_{\mathrm{S}} \pm\right.$ standard deviation) and OME in pure or complex state

\begin{tabular}{|c|c|c|c|c|}
\hline Inclusion complex & $\mathrm{S}_{\mathrm{t}}^{\mathrm{a}}(\mathrm{mg} / \mathrm{mL})$ & $\mathrm{S}_{2}^{\mathrm{b}}(\mathrm{mg} / \mathrm{mL})$ & $\mathrm{D}_{2}\left(10^{-2}\right)^{\mathrm{c}}$ & $K_{\mathrm{S}}\left(\mathrm{M}^{-1}\right)$ \\
\hline OME- $\beta \mathrm{CD}$ & $1.2 \pm 0.05$ & $1.9 \pm 0.03$ & 16.9 & $56.9 \pm 2.34$ \\
\hline OME-M $\beta \mathrm{CD}$ & $1.1 \pm 0.03$ & $3.9 \pm 0.05$ & 19.4 & $77.4 \pm 1.39$ \\
\hline
\end{tabular}

${ }^{a}$ OME solubility in borate buffer $\mathrm{pH}=10$

b OME solubility in $\mathrm{CD}$ solutions $[1.5 \%(\mathrm{w} / \mathrm{v}) \beta \mathrm{CD}$ and $5 \%(\mathrm{w} / \mathrm{v}) \mathrm{M} \beta \mathrm{CD}]$

c Slopes of the phase-solubility diagrams achieved in inclusion complexes

the magnitude of complex formation lowering $K_{\mathrm{S}}$ values. Since, ionization is a common method for increasing the aqueous solubility of ionizable drugs, the additional drug solubilization by CDs may result in the improvement of drug solubility, by solubilization of a drug both due to CD complexation and ionization [7].

\section{Differential scanning calorimetry}

The DSC profiles of pure components (OME, $\beta \mathrm{CD}$ and $\mathrm{M} \beta \mathrm{CD}$ ) and binary systems in the melting region of the drug and carriers dehydration are shown in Fig. 3. The thermal curve of OME was typical of a crystalline anhydrous substance with a sharp fusion endotherm at $159.8^{\circ} \mathrm{C}$, corresponding to the melting point of the drug, followed by an exothermal effect at $173.9^{\circ} \mathrm{C}$, attributed to its thermal decomposition [8]. The DSC curves of $\beta C D$ and $\mathrm{M} \beta \mathrm{CD}$ showed a broad endothermic effect around $85^{\circ} \mathrm{C}$ and $64{ }^{\circ} \mathrm{C}$, respectively, associated to crystal water losses from CDs [9]. In PM DSC curves it was clearly distinguishable OME endothermic peak around $159.81-160.05{ }^{\circ} \mathrm{C}$ in addition to the CDs dehydration effect. These curves are in fact the DSC curves superpositions of the individual components [10], showing the absence of interaction between the drug and CDs in such systems.

Considering KN systems, there was a substantial size reduction, broadening and a shift to lower temperatures of the drug melting point $\left(149.5^{\circ} \mathrm{C}\right.$ and $145.7^{\circ} \mathrm{C}$ for $\beta \mathrm{CD}$ and $\mathrm{M} \beta \mathrm{CD}$, respectively). This effect, specially observed for OME:M $\beta \mathrm{CD}$ KN product, could be ascribed to some drug-CD interaction [11]. This fact was also observed in OME: $\beta C D$ SD system. In these systems we can assume the occurrence of a reduction in drug crystallinity or probably a partial dispersion at a molecular level at the solid product [12], but this was not indicative of a true inclusion complex formation.

Oppositely, the disappearance of the OME melting point in the OME:M $\beta$ CD SD system and in both $\mathrm{LPh}$ products suggest the formation of amorphous solid dispersion and/or inclusion complexes [13]. These results are a strong evidence that only OME:M $\beta \mathrm{CD}$
$\mathrm{SD}$ system and $\mathrm{LPh}$ products can be considered true inclusion complexes.

\section{Conclusions}

Those preliminary results suggest that OME forms inclusion complexes with $\beta \mathrm{CD}$ and $\mathrm{M} \beta \mathrm{CD}$ in aqueous solution with a 1:1 stoichiometry. Furthermore, $K_{\mathrm{S}}$ values indicate that the derivative of $\beta \mathrm{CD}(\mathrm{M} \beta \mathrm{CD})$ formed a more stable inclusion complex with $\mathrm{OME}$ than those with $\beta \mathrm{CD}$, probably because the higher cavity hydrophobicity of $\mathrm{M} \beta \mathrm{CD}$ comparatively to $\beta \mathrm{CD}$ cavity. OME solubility increased by $\mathrm{CD}$ complexation being this effect more pronounced with $\mathrm{M} \beta \mathrm{CD}$. The physicochemical solid-state characterization of OME: $\beta \mathrm{CD}$ and OME:M $\beta \mathrm{CD}$ inclusion complexes by DSC and other experimental data, as yet not published, indicated the presence of new solid phases, some of them in an amorphous state and gave strong evidence of the formation of inclusion complexes between $\mathrm{OME}$ and $\mathrm{CDs}(\beta \mathrm{CD}$ and $\mathrm{M} \beta \mathrm{CD})$ particularly for OME:M $\beta C D$ spray dried system and lyophilized products for both CDs.

Acknowledgements This work was financially supported by a grant (Praxis SFRH/BD/19175/2004) from FCT (Fundação para a Ciência e a Tecnologia, Portugal). The authors would like to thank Belmac Laboratory, S.A. (Barcelona, Spain) for the kindly donation of OME and Roquette (Lestrem, France) for their support providing $\beta \mathrm{CD}$ and $\mathrm{M} \beta \mathrm{CD}$.

\section{References}

1. Berzas Nevado, J.J., Castañeda Peñalvo, G., Rodríguez Dorado, R.M.: Method development and validation for the separation and determination of omeprazole enantiomers in pharmaceutical preparations by capillary electrophoresis. Analy. Chim. Acta 533, 127-133 (2005)

2. Piel, G., Pirotte, B., Delneuville, I., Neven, P., Llabres, G., Delarge, J., Delattre, L.: Study of the influence of both cyclodextrins and L-lysine on the aqueous solubility of nimesulide; isolation and characterization of nimesulide-L-lysine-cyclodextrin complexes. J. Pharm. Sci. 86, 475-480 (1997) 
3. Ventura, C.A., Giannone, I., Paolino, D., Pistarà, V., Corsaro, A., Puglisi, G.: Preparation of celecoxib-dimethyl- $\beta$ cyclodextrin inclusion complex: characterization and in vitro permeation study. Eur. J. Med. Chem. 40, 624-631 (2005)

4. Giordano, F., Nóvak, C., Moyano, J.R.: Thermal analysis of cyclodextrins and their inclusion compounds. Thermochim. Acta 380, 123-151 (2001)

5. Higuchi, T., Connors, K.A.: In: Reill, C.N., (ed.) Phase-solubility Techniques Advanced in Analytical Chemistry and Instrumentation, pp. 117-212. Wiley-Intersciences, New York (1965)

6. Arias, M.J., Moyano, J.R., Muñoz, P., Ginés, J.M., Justo, A., Giordano, F.: Study of omeprazole- $\gamma$-cyclodextrin complexation in the solid state. Drug Dev. Indust. Pharm. 26, 253-259 (2000)

7. Loftsson, T., Ólafsdóttir, B.J., Frioriksdóttir, H., Jónsdóttir, S.: Cyclodextrin complexation of NSAIDs physicochemical characteristics. Eur J Pharm Sci 1, 95-101 (1993)

8. Ruiz, M.A., Reyes, I., Parera, A., Gallardo, V.: Determination of the stability of omeprazole by means of differential scanning calorimetry. J. Thermal Anal. Calorimetry 51, 2935 (1998)
9. Hassan, M., Suleiman, M., Najib, N.: Improvement of the in vitro dissolution characteristics of famotidine by inclusion in $\beta$-cyclodextrin. Int. J. Pharm. 58, 19-24 (1990)

10. Perdomo-López, I., Rodríguez-Pérez, A.I., Yzquierdo-Peiró, J.M., White, A., Estrada, E.G., Villa, T.G., Torres-Labandeira, J.J.: Effect of cyclodextrins on the solubility and antimycotic activity of sertaconazole: experimental and computational studies. J. Pharm. Sci. 91, 2408-2415 (2002)

11. Mura, P., Adragna, E., Rabasco, A., Moyano, J., PérezMartinez, J., Arias, M., Ginés, J.: Effects of the host cavity size and the preparation method on the physicochemical properties of Ibuproxam-cyclodextrin systems. Drug Dev. Indus. Pharm. 25, 279-287 (1999)

12. Ribeiro, L.S.S., Ferreira, D.C., Veiga, F.J.B.: Physicochemical investigation of the effects of water-soluble polymers on vinpocetine complexation with $\beta$-cyclodextrin and its sulfobutyl ether derivative in solution and solid state. Eur. J. Pharm. Sci. 20, 253-266 (2003)

13. Esclusa-Díaz, M., Torres-Labandeira, J., Kata, M., Vila-Jato, J.: Inclusion complexation of glibenclamide with 2-hydroxypropyl- $\beta$-cyclodextrin in solution and in solid state. Euro. J. Pharm. Sci. 1, 291-296 (1994) 